Session 2553

\title{
Freshman Engineering Courses at Manhattan College - Lessons Learned
}

\author{
Bahman Litkouhi and Philip J. Pritchard \\ Manhattan College
}

\begin{abstract}
In 1996 the School of Engineering introduced two new three-credit interdisciplinary freshman engineering courses, ENGS115 and ENGS116. This paper presents the steps followed in developing these courses, explains the detailed curriculum, reviews the outcomes and feedback from the students, compares the improvement in the retention rate over the past four years, and discusses our experiences and lessons learned.
\end{abstract}

\section{Introduction}

In the mid - 1990's, the School of Engineering at Manhattan College, as did many other engineering schools, recognized that it was necessary to create a smooth transition for freshman students entering an engineering program. The first year retention rate was approximately $65-70 \%$. The traditional curriculum did not allow much early direct contact between engineering students and their engineering subjects, or with their faculty. A student could drop out of the program at the end of the first year without having had any engineering experience. Accordingly, it was concluded that the departments could not wait until a student had completed all pre-requisite math and science courses before the student was brought into contact with his or her department.

With these concerns and keeping in mind the ABET 2000 requirements, in 1996 a group of faculty representing the five engineering programs at that time, worked together to plan for new introductory engineering courses. The outcome of their efforts resulted in two threecredit freshman courses, ENGS115 and ENGS116. It is noteworthy to mention that 1996 was not the first time that the School of Engineering had attempted to have freshman introductory courses. Orientation courses were introduced six years earlier, but did not receive favorable ratings, and consequently, were dropped from the curriculum a few years later. The poor acceptance of these courses was mainly due to the large classes, the pass/fail grading method, the fact that it was zero credit, and the lack of hands-on-experience and sufficient engineering activities during the semester.

The lessons learned from the previous orientation courses were used when planning the new courses. The new courses were designed to not only make the transition from high school to college a more motivating and exciting experience for students, but also to provide them with the basic engineering skills that would be useful in their future courses. In particular, the new courses were designed to meet the following objectives: 
- Introduce the students to campus resources at an early stage

- Help students make a smooth transition into an engineering program

- Engender motivation and excitement for engineering

- Allow early direct contact of freshmen with engineering faculty (engaging the faculty as mentors)

- Enhance students' effectiveness, and cultivate a positive attitude toward the learning process

- Provide an early exposure to engineering concepts, the design process, and problem solving methodologies

- Convey the importance and relevance of other subjects (math, science, economics, etc.) to engineering

- Develop written and oral communication skills of engineering students

- Help students to find out about and select the engineering disciplines that best match their individual goals

- Introduce students to effective hands-on experiences with computers

These objectives have been distributed throughout the two courses. The first course, ENGS1 15: - Introduction of Engineering, introduces the new engineering students to the various engineering disciplines and the design process, while in the second course, ENGS1 16: - Computer Programming for Engineers, the emphasize is more on computer applications and programming. Each course is taught by six engineering faculty from different departments to a total of about 125 students each semester. Due to the hands on nature of these courses, the classes are small and limited to an enrollment of about 20 students. Both courses encourage student-teacher and student-student interactions. The detailed curricula are provided in the following sections.

\section{Curriculum}

\section{ENGS115:- Introduction of Engineering}

This course is organized around a semester-long design project. The emphasis is on engineering problem solving methodologies and computational techniques. Basic engineering concepts and analyses related to the design project are discussed on a need-toknow basis. The course includes five hands-on laboratory sessions; site visits to local engineering firms and manufacturing plants; ethics and professional responsibilities; and economic concerns associated with the engineering design process. Teamwork is strongly encouraged. The students are evaluated based on the following components:

\section{Project (40\% of final grade)}

The students work through the design project in teams of three or four with an emphasis on active learning. Each team is required to build and operate its design, competing in a headto-head performance competition. Each team is also required to keep a detailed project Logbook, submit a final Written Report, and make an Oral Presentation to a panel of judges.

The Logbook is for documenting team's discoveries and the progress of the project as the team members work through and evaluate various approaches, and draw conclusions that 
lead them to their final design. The written report is a maximum five pages, double-spaced, typewritten report excluding title page, table of content, abstract, diagrams, or design specification drawings. All tables, diagrams, and drawings presented in the report are to be computer generated (using Excel, AutoCAD, for example). The oral presentations are judged on content and delivery. The intent is to judge the team's ability to clearly communicate their understanding of what the team did and why.

\section{Laboratories (40\% of final grade)}

There are five laboratories, one associated with each of the five major engineering disciplines, civil, chemical, electrical, environmental, and mechanical. Individual student short reports are required for each laboratory. The short reports are no more than 2 to 3 pages of double-spaced text, with as many as figures as required. Each report is worth 8 points, and must be submitted within a week of the lab.

\section{Homework and Instructor Evaluation (20\% of final grade)}

There are several homework assignments during the semester. These include Word, Excel, and AutoCAD homework sets, and the Ethics Report.

\section{ENGS116:- Computer Programming for Engineers}

This course is an introductory course in computer applications and programming. The course is modular in structure, in that, it is comprised of discrete topics in graphics, mathematics and analysis, and programming. As in the first course, it is organized around a semester-long project - this time focussing on computer programming. Teams of students work on different assignments related to their project, using the skills they have acquired during the semester. As the semester proceeds, most of the assignments become the foundation for the final report, which is due to the end of the semester. The students must also present their final product to a panel of judges. There is also a mid-term exam and a common final exam. The students are evaluated based on the following components:

\section{Project (20\% of final grade)}

Teams of three or four students do the project. Each team is required to submit a project Proposal (to define the project and its objectives) at the beginning of the semester, a midterm progress report and a final Written report (12\%) to explain their project results and methodology. The teams are also required to make an Oral presentation (8\%) to a panel of judges, and answer questions regarding all aspects of their project.

\section{Introduction, Excel (1 week, HW = 5\% of final grade)}

This includes a description of facilities (e-mail, etc.). Features of Excel such as equation solving, evaluating integrals, and using the IF function are reviewed.

\section{Programming Module, Visual Basic (8 weeks, HW and Quizzes $=35 \%$ of grade)}

The coverage includes: introductory concepts of Visual Basic, program development cycle, programming tools, the programming environment, VB objects, VB events, numbers, strings, input and output, built-in functions, subprograms, modular design, structured programming, 
relational and logical operators, IF blocks, select case blocks, use of looping, creating and using arrays, 2-D arrays, VB graphics.

Mathematics Module, Mathcad (4weeks, HW and Quizzes $=15 \%$ of final grade)

This is a review of Mathcad basics, such as elementary operations, use of units, use of solve blocks, graphing, built-in features (differentiation, integration, symbolic math, etc.)

\section{Final Presentations}

Student teams present a computer slide show using PowerPoint, to a panel of judges.

\section{Mid-Term Exam (10\% of final grade)}

There is a written or hands-on exam administered during the regular class time by each instructor.

\section{Final Exam (15\% of grade)}

A common multiple-choice exam reviewing concepts learned in each module is given at the end of the semester.

\section{Faculty}

The faculty selected for teaching these courses had to satisfy two criteria: between the six faculty it was desirable to have each of the five disciplines represented; they should be chosen from among each department's "star" teachers. The latter criterion was very important for creating an initial favorable impression with the freshmen - starting engineering is already quite daunting for students without having what could be described as "harder" teachers. This often meant that younger (non-tenured, or at lower rank) faculty were selected, so that it was decided that teaching these courses would be equivalent to teaching two sections of another course. In this way these younger faculty would not be overburdened and still be able to pursue tenure and/or promotion activities. These course were assigned extra teaching loads for another reason: teachers would be strongly encouraged to meet with student groups on a regular and repeated basis, explicitly for help with student projects, but also implicitly for mentoring and "bonding" purposes.

\section{Feedback From Students}

At the conclusion of each semester, input was sought from the students in both courses using two different course evaluation forms- one for general questions and the other on teamwork. In general, we were encouraged by the favorable responses these courses received from the students. For simplicity, only the results of the first course (ENGS115) are discussed here. For more information on the second course (ENGS116), please see reference [1].

Tables 1 and 2 show the feedback from the students in ENGS115 over the past few years. Table 1 demonstrates their teamwork experience, while Table 2 shows their responses to some general questions. It is interesting to note that for the majority of the questions, more than $80 \%$ of the students either agreed or strongly agreed with the statements given in the surveys. In response to the general question 5 (Table 1), $85 \%$ to $90 \%$ of the students 
believed that the design project provided a valuable dimension to the course. It is also interesting to note that in response to the general questions 2 and 3,91\% to $98 \%$ of the students were pleased with the role of their instructors in this course.

\section{Table 1. General Questions, ENGS115}

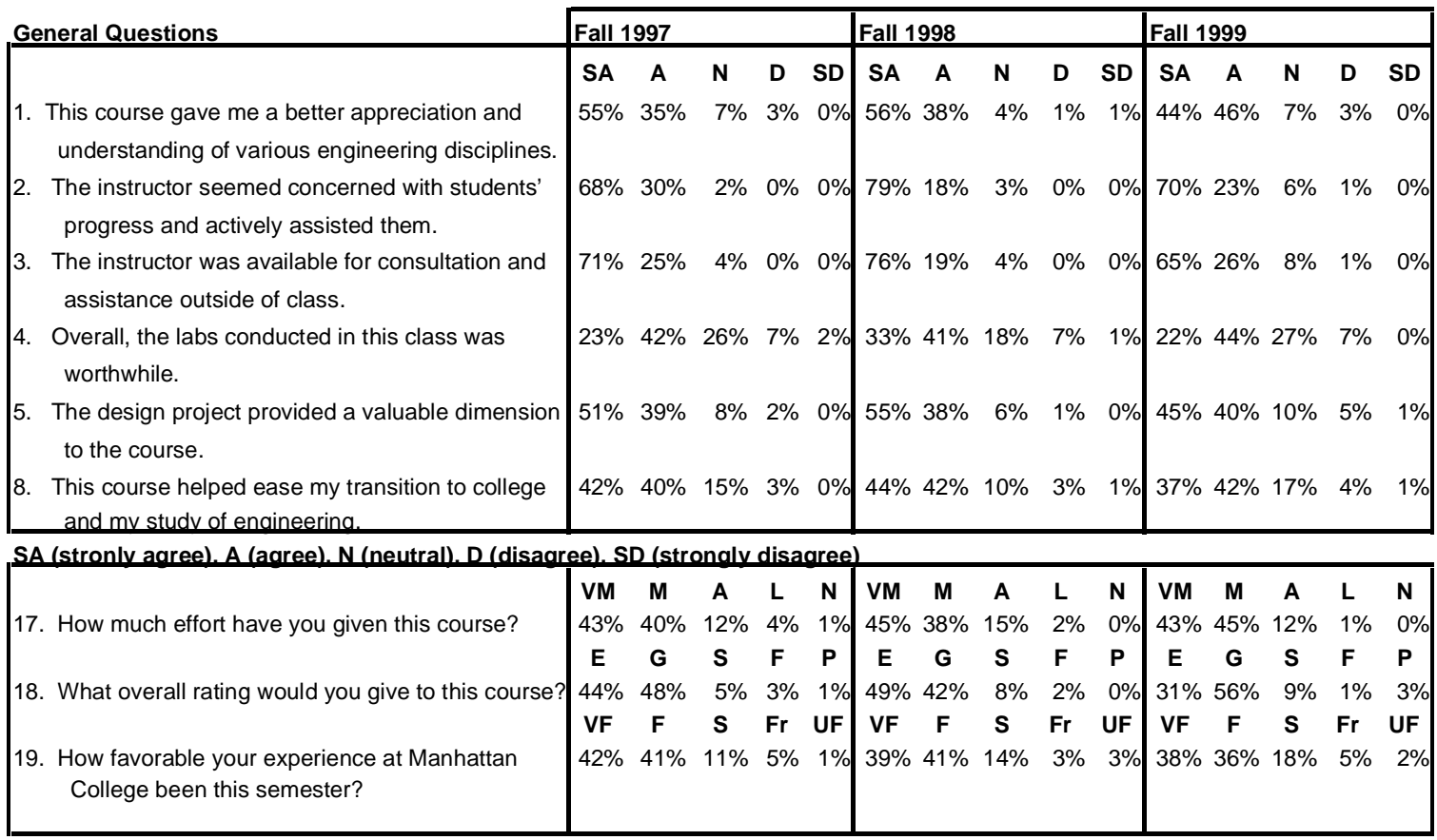

VM (very much), M (much), A (adequate), L (little), N (none)

E (excellent), G (good), S (satisfactory), F (fair), P (poor)

VF (very favorable), F (favorable), S (satisfactory), Fr (fair), UF (unfavorable)

Table 2. Teamwork Questions, ENGS115

\begin{tabular}{|c|c|c|c|c|c|c|c|c|c|c|c|c|c|c|c|c|c|c|c|c|}
\hline \multirow{3}{*}{ Teamwork Questions } & \multirow{2}{*}{\multicolumn{5}{|c|}{ Fall 1996}} & \multirow{2}{*}{\multicolumn{5}{|c|}{ Fall 1997}} & \multirow{2}{*}{\multicolumn{5}{|c|}{ Fall 1998}} & \multirow{2}{*}{\multicolumn{5}{|c|}{ Fall 1999}} \\
\hline & & & & & & & & & & & & & & & & & & & & \\
\hline & SA & A & $N$ & D & SD & SA & A & $\mathbf{N}$ & D & SD & SA & A & $\mathbf{N}$ & D & SD & SA & A & $\mathbf{N}$ & D & SD \\
\hline $\begin{array}{l}\text { 1. I felt comfortable working } \\
\text { with this team. }\end{array}$ & $44 \%$ & $38 \%$ & $12 \%$ & $4 \%$ & $2 \%$ & $53 \%$ & $33 \%$ & $9 \%$ & $2 \%$ & $3 \%$ & $49 \%$ & $29 \%$ & $14 \%$ & $3 \%$ & $5 \%$ & $45 \%$ & $39 \%$ & $9 \%$ & $3 \%$ & $3 \%$ \\
\hline $\begin{array}{l}\text { 2. I was an active participant } \\
\text { on my team. }\end{array}$ & $66 \%$ & $26 \%$ & $6 \%$ & $2 \%$ & $0 \%$ & $58 \%$ & $34 \%$ & $7 \%$ & $1 \%$ & $0 \%$ & $66 \%$ & $26 \%$ & $5 \%$ & $1 \%$ & $2 \%$ & $59 \%$ & $36 \%$ & $3 \%$ & $1 \%$ & $1 \%$ \\
\hline $\begin{array}{l}\text { 3. I listened to everyone on my } \\
\text { team. }\end{array}$ & $51 \%$ & $35 \%$ & $6 \%$ & $0 \%$ & $8 \%$ & $66 \%$ & $25 \%$ & $6 \%$ & $2 \%$ & $1 \%$ & $52 \%$ & $39 \%$ & $6 \%$ & $2 \%$ & $2 \%$ & $52 \%$ & $38 \%$ & $7 \%$ & $1 \%$ & $2 \%$ \\
\hline $\begin{array}{l}\text { 4. I encouraged \& praised } \\
\text { others on my team. }\end{array}$ & $50 \%$ & $25 \%$ & $17 \%$ & $2 \%$ & $6 \%$ & $50 \%$ & $34 \%$ & $10 \%$ & $2 \%$ & $4 \%$ & $46 \%$ & $41 \%$ & $9 \%$ & $3 \%$ & $2 \%$ & $37 \%$ & $48 \%$ & $8 \%$ & $7 \%$ & $0 \%$ \\
\hline $\begin{array}{l}\text { 5. I felt encouraged by } \\
\text { people on my team. }\end{array}$ & $46 \%$ & $21 \%$ & $19 \%$ & $8 \%$ & $6 \%$ & $49 \%$ & $31 \%$ & $10 \%$ & $7 \%$ & $2 \%$ & $36 \%$ & $36 \%$ & $15 \%$ & $8 \%$ & $5 \%$ & $25 \%$ & $47 \%$ & $23 \%$ & $2 \%$ & $3 \%$ \\
\hline $\begin{array}{l}\text { 6. I asked for explanations/help } \\
\text { when I didn't understand. }\end{array}$ & $46 \%$ & $38 \%$ & $10 \%$ & $6 \%$ & $0 \%$ & $51 \%$ & $29 \%$ & $12 \%$ & $5 \%$ & $3 \%$ & $44 \%$ & $39 \%$ & $11 \%$ & $4 \%$ & $2 \%$ & $45 \%$ & $43 \%$ & $9 \%$ & $1 \%$ & $1 \%$ \\
\hline $\begin{array}{l}\text { 7. I explained/helped someone } \\
\text { who didn't understand. }\end{array}$ & $41 \%$ & $41 \%$ & $14 \%$ & $2 \%$ & $2 \%$ & $46 \%$ & $38 \%$ & $13 \%$ & $2 \%$ & $0 \%$ & $55 \%$ & $30 \%$ & $15 \%$ & $0 \%$ & $1 \%$ & $36 \%$ & $55 \%$ & $9 \%$ & $0 \%$ & $0 \%$ \\
\hline 8. I felt comfortable with my role. & $49 \%$ & $30 \%$ & $12 \%$ & $5 \%$ & $5 \%$ & $64 \%$ & $28 \%$ & $7 \%$ & $1 \%$ & $0 \%$ & $69 \%$ & $23 \%$ & $5 \%$ & $0 \%$ & $3 \%$ & $52 \%$ & $43 \%$ & $5 \%$ & $0 \%$ & $0 \%$ \\
\hline $\begin{array}{l}\text { 9. I found this group activity to } \\
\text { be a worthwhile experience. }\end{array}$ & $38 \%$ & $33 \%$ & $12 \%$ & $4 \%$ & $13 \%$ & $64 \%$ & $22 \%$ & $11 \%$ & $3 \%$ & $0 \%$ & $64 \%$ & $24 \%$ & $5 \%$ & $5 \%$ & $3 \%$ & $53 \%$ & $31 \%$ & $10 \%$ & $5 \%$ & $1 \%$ \\
\hline $\begin{array}{l}\text { 10. I enjoyed working with } \\
\text { my classmates in teams. }\end{array}$ & $35 \%$ & $39 \%$ & $18 \%$ & $2 \%$ & $6 \%$ & $64 \%$ & $21 \%$ & $10 \%$ & $3 \%$ & $2 \%$ & $62 \%$ & $20 \%$ & $10 \%$ & $3 \%$ & $5 \%$ & $47 \%$ & $42 \%$ & $3 \%$ & $5 \%$ & $3 \%$ \\
\hline
\end{tabular}

SA (strongly agree), A (agree), N (neutral), D (disagree), SD (strongly disagree)

Proceedings of the 2001 American Society for Engineering Education Annual Conference \& Exposition Copyright (C) 2001, American Society for Engineering Education 
The only area of concern that was rated relatively lower compared to the other questions, was the laboratory experience. About one-third of the students felt either neutral or disagreed with the given statement that "the laboratory work was a worthwhile experience". Overall, in response to the general question 18 , approximately $87 \%$ to $92 \%$ of the students rated this course either excellent or good (marked the highest and next to highest categories). Some graphical presentations of the surveys are provided in Figure 1.

With regard to the retention rate, the results are also quite positive. Table 3 shows data on the year-to-year retention rates for the freshman engineering students. It can be seen that after introduction of the new course in the 1996-97 academic year, the retention rate for both the fall and spring semesters have consistently improved by approximately 7 to 12 percent.

Table 3. Year to Year Freshman Retension Within School of Engineering

\begin{tabular}{|c|c|c|c|c|}
\hline \multirow[t]{2}{*}{ 1995-96 Academic Year } & \multicolumn{2}{|c|}{ Fall 95 to Spring 96} & \multicolumn{2}{|c|}{ Spring 96 to Fall 96} \\
\hline & $\begin{array}{c}\text { Raw Data } \\
77 / 105 \\
\end{array}$ & $\begin{array}{c}\text { Percent } \\
73 \% \\
\end{array}$ & $\begin{array}{c}\text { Raw Data } \\
69 / 105 \\
\end{array}$ & $\begin{array}{c}\text { Percent } \\
66 \% \\
\end{array}$ \\
\hline 1996-97 Academic Year & \multicolumn{2}{|c|}{ Fall 96 to Spring 97} & \multicolumn{2}{|c|}{ Spring 97 to Fall 97} \\
\hline & $\begin{array}{c}\text { Raw Data } \\
107 / 114\end{array}$ & $\begin{array}{c}\text { Percent } \\
92 \%\end{array}$ & $\begin{array}{c}\text { Raw Data } \\
89 / 114\end{array}$ & $\begin{array}{c}\text { Percent } \\
78 \%\end{array}$ \\
\hline \multirow[t]{2}{*}{ 1997-98 Academic Year } & \multicolumn{2}{|c|}{ Fall 97 to Spring 98} & \multicolumn{2}{|c|}{ Spring 98 to Fall 98} \\
\hline & $\begin{array}{c}\text { Raw Data } \\
82 / 92 \\
\end{array}$ & $\begin{array}{c}\text { Percent } \\
89 \% \\
\end{array}$ & $\begin{array}{c}\text { Raw Data } \\
70 / 92\end{array}$ & $\begin{array}{c}\text { Percent } \\
76 \% \\
\end{array}$ \\
\hline \multirow[t]{2}{*}{ 1998-99 Academic Year } & \multicolumn{2}{|c|}{ Fall 98 to Spring 99} & \multicolumn{2}{|c|}{ Spring 99 to Fall 99} \\
\hline & $\begin{array}{c}\text { Raw Data } \\
118 / 125\end{array}$ & $\begin{array}{c}\text { Percent } \\
94 \%\end{array}$ & $\begin{array}{c}\text { Raw Data } \\
91 / 125\end{array}$ & $\begin{array}{c}\text { Percent } \\
73 \%\end{array}$ \\
\hline \multirow[t]{2}{*}{ 1999-00 Academic Year } & \multicolumn{2}{|c|}{ Fall 99 to Spring 00} & \multicolumn{2}{|c|}{ Spring 00 to Fall 00} \\
\hline & $\begin{array}{c}\text { Raw Data } \\
102 / 117\end{array}$ & $\begin{array}{c}\text { Percent } \\
87 \%\end{array}$ & $\begin{array}{c}\text { Raw Data } \\
88 / 117\end{array}$ & $\begin{array}{c}\text { Percent } \\
75 \%\end{array}$ \\
\hline
\end{tabular}

\section{Concluding Remarks}

The new freshman courses have been very successful in improving the retention of engineering students, and will continue on a continual-modification basis. Students exit these courses with a clarified and improved impression of what engineering in general and their major in particular are about. In addition, students become much more comfortable about visiting engineering departments on a casual basis - they feel like they belong. The caveat with regard to these courses is that they are labor-intensive: they require a major commitment of time and effort from individual faculty, and a high degree of collaboration between departments. 

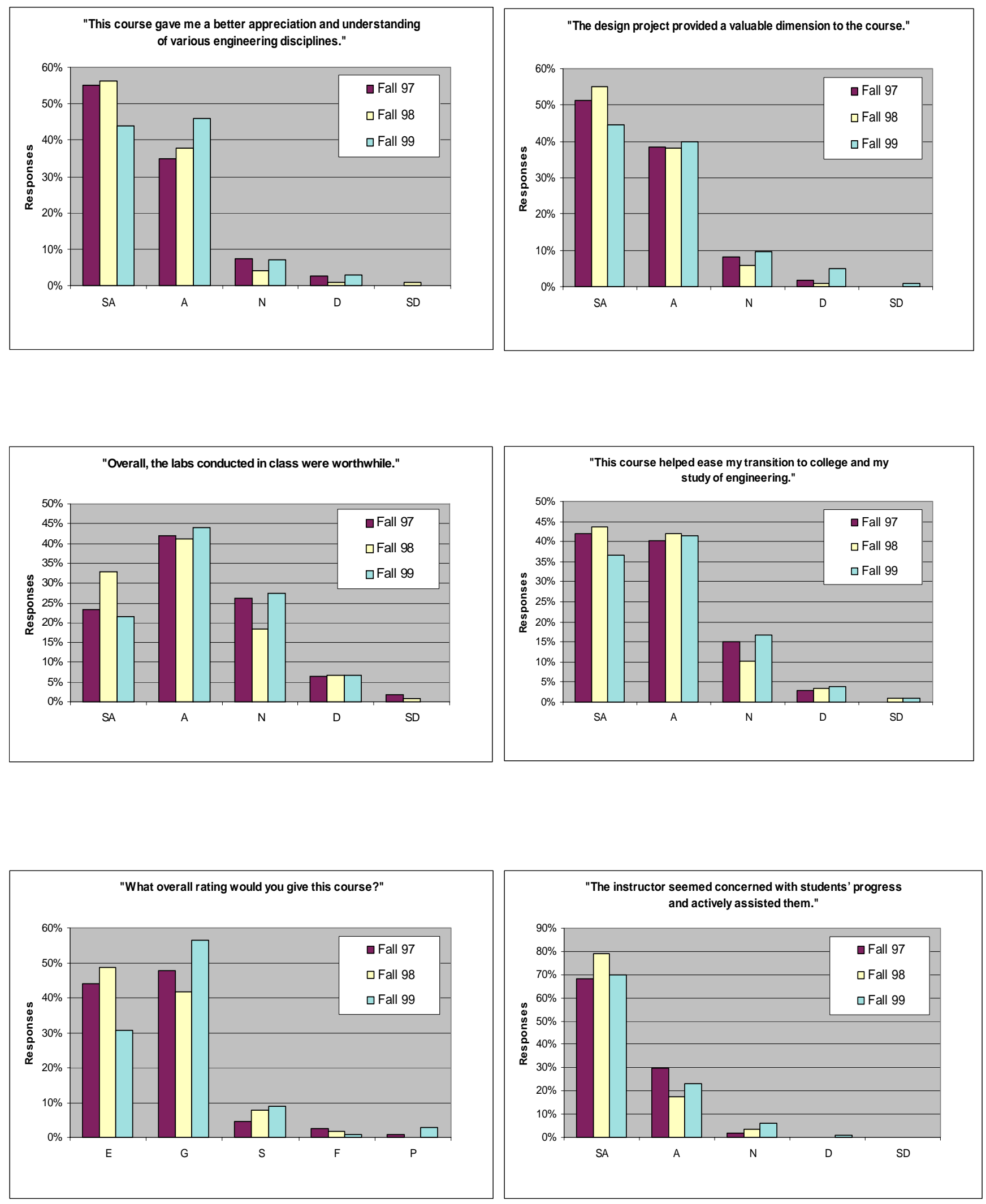

Figure 1. Slide Presentation of the Student Survey

Proceedings of the 2001 American Society for Engineering Education Annual Conference \& Exposition Copyright (C) 2001, American Society for Engineering Education 
Bibliography

1. Naraghi, M.H.N. and Litkouhi, B., "An effective Approach for Teaching Computer Programming to Freshman Engineering Students," Accepted for presentation in 2001 ASEE Annual Conference, June 24 - 27, Albuquerque, NM.

\section{BAHMAN LITKOUHI}

Bahman Litkouhi is a Professor and the Chair of Mechanical Engineering Department at Manhattan College. He also served as the Director of Freshman Engineering Program in the School of Engineering for four years (1996-2000). Dr. Litkouhi received his M.S. and Ph.D. degrees in Mechanical Engineering from Michigan State University. His interests include analysis and design of thermal/fluid systems, bioengineering modeling, and computational heat transfer. Dr. Litkouhi is a registered Professional Engineer in New York State and is actively involved in joint research with industry. He can be contacted at blitkouh@manhattan.edu.

\section{PHILIP PRITCHARD}

Philip J. Pritchard is an Associate Professor of Mechanical Engineering at Manhattan College. He is Director of Freshman Engineering at Manhattan College. He received his B. Tech. at the University of Bradford (UK), an M.S. at SUNY Stony Brook, and an M. Phil. and Ph.D. at Columbia. His main interests are now in the area of engineering education. In recent years he has specialized in the use of computer software in teaching engineering analysis, in particular the use of Mathcad and Excel. Further information is available at http://www.engineering.manhattan.edu/mechanical/faculty/pritchar.html. He can be contacted at ppritcha@manhattan.edu. 